\title{
PERANCANGAN SISTEM INVENTORY RUANG KELAS DENGAN PENDEKATAN METODE QUALITY CONTROL STATISTICAL SAMPLING BERBASIS WEB STUDI KASUS : INSITUT TEKNOLOGI TELKOM PURWOKERTO
}

\author{
1) Diovianto Putra Rakhmadani, ${ }^{2)}$ Faisal Dharma Adhinata, ${ }^{3)}$ Ariq Cahya Wardhana \\ ${ }^{1,2,3)}$ Program Studi Rekayasa Perangkat Lunak, Fakultas Informatika, Institut Teknologi Telkom Purwokerto \\ 1,2,3) Jl. DI Panjaitan No 128 Purwokerto - Jawa Tengah - Indonesia \\ E-mail : diovianto@ittelkom-pwt.ac.id,faisal@ittelkom-pwt.ac.id,ariq@ittelkom-pwt.ac.id
}

\begin{abstract}
ABSTRAK
Ruang kelas merupakan tempat utama dalam pelaksanaan kegiatan belajar mengajar. Kenyamanan ruang kelas secara tidak langsung juga mempengaruhi suasana belajar dan tingkat kenyamanan mahasiswa dalam pelaksanaan kegiatan belajar mengajar. Di dalam kegiatan operasionalnya, ruang kelas memiliki beberapa alat penunjang seperti papan tulis, proyektor, pendingin ruangan, kursi, dan meja. Benda-benda tersebut seringkali mengalami kendala seperti kerusakan ringan, penurunan fungsi, hingga kerusakan berat. Adanya kendala-kendala tersebut mampu menjadikan kurang berkualitasnya kegiatan belajar mengajar di suatu ruang kelas akademik. Sarana dan prasarana untuk menunjang kegiatan belajar mengajar yang berkualitas memerlukan sebuah sistem informasi inventory dengan metode quality control untuk memastikan kualitas sarana yang ada di ruang kelas tetap terjaga. Penelitian ini menggunakan metode pengembangan perangkat lunak Waterfall dan menghasilkan suatu sistem terkomputerisasi berbasis web yang dapat digunakan untuk memantau kualitas sarana ruang kelas hingga penindaklanjutan. Dengan adanya sistem ini, maka kualitas sarana dan prasarana di dalam ruang kelas tetap terjaga
\end{abstract}

Kata Kunci: Inventory, Pengendalian Mutu, Model Air Terjun, Sistem Informasi, Situs Web

\section{ABSTRACT}

The classroom is the principal place in the implementation of teaching and learning activities. Classroom comfort indirectly affects the learning atmosphere and the comfort level of students in implementing teaching and learning activities. In its operational activities, classrooms have several supporting tools such as blackboards, projectors, air conditioners, chairs, and desks. These objects often experience problems such as minor damage, decreased function, to heavy damage. The existence of these obstacles can make teaching and learning activities less qualified in an academic classroom. Facilities and infrastructure to support quality teaching and learning activities require an inventory information system with quality control methods to ensure the classroom's quality of facilities is maintained. This research uses the Waterfall software development method and produces a web-based computerized system that can be used to monitor the quality of classroom facilities and follow-up. With this system, the quality of facilities and infrastructure in the classroom is maintained.

Keyword: Inventory, Quality Control, Waterfall Model, Information System, Website

\section{PENDAHULUAN}

Lingkungan kampus merupakan lingkungan akademis yang turut membantu tingkat kenyamanan kegiatan belajar mengajar di lingkup pendidikan sarjana. Ruang kelas merupakan bagian dari lingkungan kampus dan merupakan tempat dimana para mahasiswa menghabiskan waktu bertahun-tahun dalam mengikuti proses kegiatan belajar mengajar hingga lulus. tata ruang kelas berarti membangun dan memelihara lingkungan kelas yang kondusif bagi pembelajaran dan prestasi mahasiswa [1]. Mahasiswa dapat belajar lebih banyak di beberapa lingkungan kelas dibandingkan lingkungan kelas yang lainnya. Ruang kelas yang baik turut membentuk mahasiswa dalam menikmati jalannya kegiatan belajar mengajar. Agar tercipta suasana yang menggairahkan, maka suatu ruang kelas harus dijaga kualitasnya. Dengan metode Quality Control, maka suatu ruang kelas dapat terus dipantau mengenai kualitasnya guna menghadirkan tempat yang sangat mendukung dalam kegiatan belajar mengajar mahasiswa. Institut Teknologi Telkom Purwokerto (ITTP) merupakan sebuah perguruan tinggi swasta yang bertransformasi dari Akademi Telekomunikasi (AKATEL) Sandhy Putra 
Telkom yang telah berdiri sejak tahun 2002. Di dalam kegiatan operasionalnya, ITTP menggunakan ruang kelas sebagai sarana belajar mengajar utama antara dosen dengan mahasiswa. Akan tetapi, banyak kendala yang berhubungan dengan pengendalian kualitas suatu ruang kelas, seperti kerusakan pada meja ataupun kursi mahasiswa yang mengakibatkan terganggunya kenyamanan para mahasiswa, AC yang seringkali tidak menyala saat dibutuhkan, patahnya kursi saat digunakan yang mengakibatkan terdapat cedera pada mahasiswa, hingga kerusakan pada proyektor sehingga dapat berpotensi menghentikan kegiatan belajar mengajar secara total. Hal-hal tersebut ditengarai karena kurangnya proses pengendalian mutu (Quality Control) terhadap inventory kelas, sehingga mengharuskan ITTP untuk membuat sebuah sistem informasi inventory kelas berbasis web dengan metode quality control untuk meminimalisir hal-hal yang tidak diinginkan tersebut.

\section{METODE}

Secara garis besar, metode yang digunakan di dalam penelitian ini terbagi menjadi 3, yaitu metode pengembangan perangkat lunak, metode pemrograman berbasis web, metode quality control, dan metode statistical sampling.

\section{Metode Pengembangan Perangkat Lunak}

Sistem informasi adalah kombinasi terorganisasi apapun dari manusia, perangkat keras, perangkat lunak, jaringan komunikasi, sumber data dan kebijakan serta prosedur yang terorganisasi yang menyimpan, mengambil, mengubah, dan memisahkan informasi dalam sebuah organisasi [2]. Di dalam penelitian ini, pengembangan sistem dilakukan dengan menggunakan metode pengembangan perangkat lunak waterfall. Model air terjun (Waterfall Model) adalah suatu pendekatan dalam pengembangan perangkat lunak yang menggambarkan metode pengembangan secara linier dan berurutan. Waterfall Model terdiri dari lima fase, setiap fase didefinisikan oleh tugas dan tujuan yang berbeda, di mana keseluruhan fase menggambarkan siklus hidup perangkat lunak hingga pengirimannya.

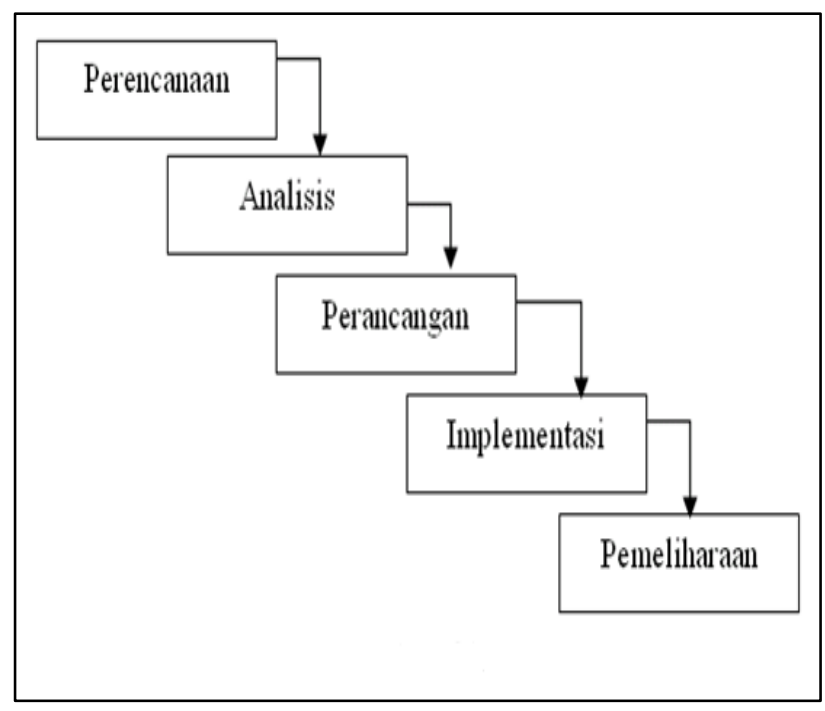

Gambar 1. Waterfall Model

\section{Pemrograman Berbasis Web}

Website adalah salah satu aplikasi yang berisikan dokumen - dokumen multimedia (teks, gambar, animasi, video) didalamnya yang menggunakan protokol HTTP (Hypertext Transfer Protocol) dan untuk mengaksesnya menggunakan perangkat lunak yang disebut browser [3]. Bahasa pemrograman yang digunakan di dalam penelitian ini adalah bahasa pemrograman PHP. PHP adalah bahasa serverside-scripting yang menyatu dengan HTML (Hypertext Markup Language) untuk membuat halaman web yang dinamis. Sedangkan untuk database menggunakan MySql. MySql adalah sebuah program pembuat database yang bersifat open source, dengan demikian siapa saja dapat menggunakannya secara bebas dan mudah untuk diaplikasikan[4]. 


\section{Quality Control}

Quality Control merupakan teknik dan kegiatan operasional yang digunakan guna memenuhi persyaratan kualitas[5]. Di dalam penelitian ini quality control menyasar seluruh unit inventory yang ada di suatu ruang kelas guna menjaga kualitas inventory yang ada.

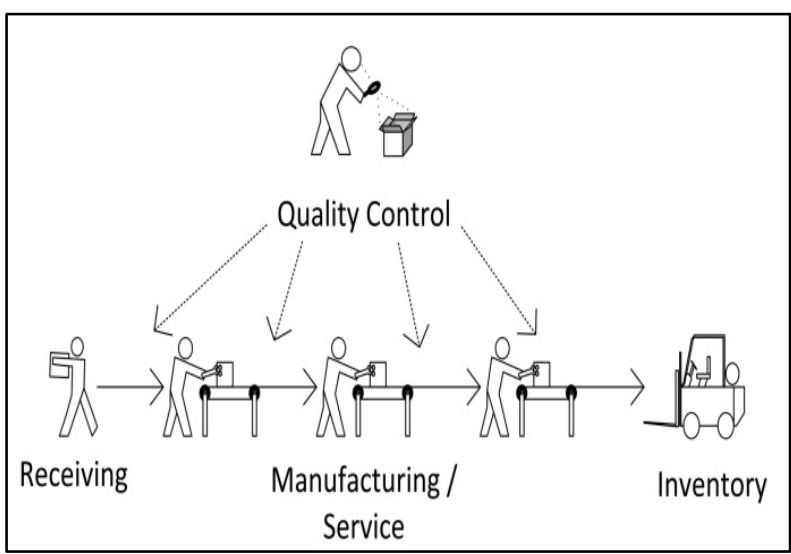

Gambar 2. Kegiatan Quality Control

\section{Statistical Sampling}

Statistical Sampling atau sampling statistik adalah penggunaan rencana sampling (sampling plan) dengan cara sedemikian rupa sehingga hukum probabilitas digunakan untuk membuat statement tentang suatu populasi.dengan syarat sampel harus dipilih secara random. Random merupakan lawan arbritrari atau judgemental. Seleksi random menawarkan kesempatan sampel tidak akan bias.

\section{HASIL}

\section{Proses Registrasi Inventory}

Semua inventory kelas yang ada di lingkungan ITTP belum teregistrasi didalam suatu sistem terkomputerisasi, oleh karena itu langkah pertama adalah melakukan penomoran di tiap inventory sesuai dengan jenis unit dan kaidah penomoran yang disepakati agar dapat didaftarkan ke dalam suatu sistem terkomputerisasi.

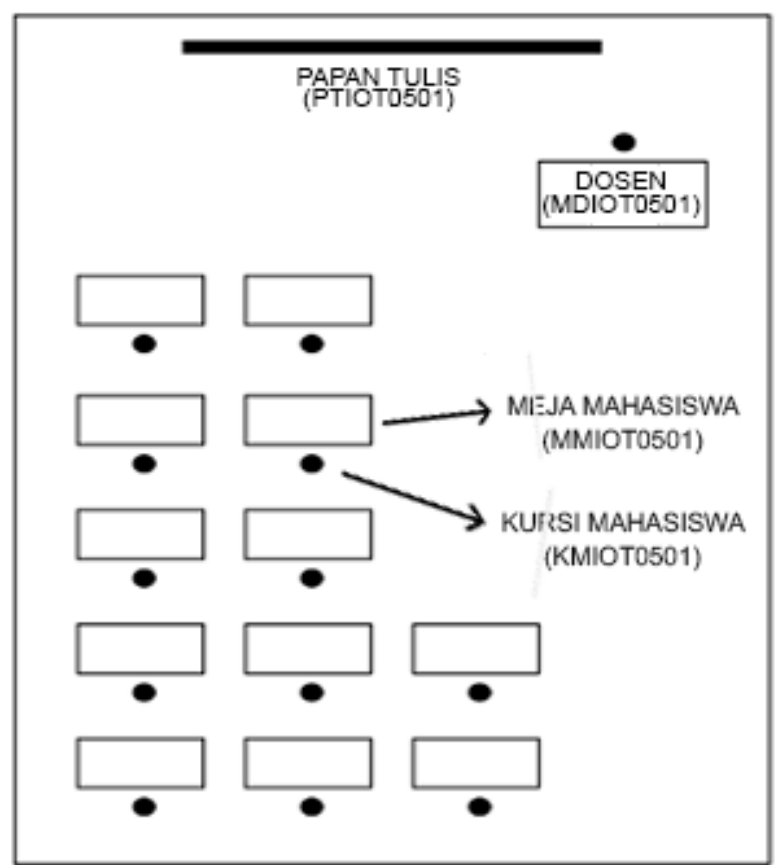

Gambar 3. Skema Registrasi Inventory

\section{Activity Diagram}

Activity Diagram merupakan bentuk visual dari alir kerja yang berisi aktivitas dan tindakan, yang juga dapat berisi pilihan, pengulangan, dan concurrency. Dalam Unified Modeling Language, diagram aktivitas dibuat untuk menjelaskan aktivitas komputer maupun alur aktivitas dalam organisasi. Berdasarkan hasil penelitian terdapat beberapa entitas dalam activity diagram, yaitu :

a. Petugas Inventory, yaitu bagian yang bertanggungjawab terhadap pendataan inventory yang masuk maupun keluar di tiap ruang kelas ITTP.

b. Penjamin Mutu, yaitu bagian yang berfungsi untuk memastikan mutu dari setiap ruang kelas dan memastikan mempunyai inventory yang cukup memadai dan tetap terjaga kualitasnya, dan mampu melakukan pengadaan atau penggantian inventory yang dirasa tidak cukup layak untuk dipertahankan. 


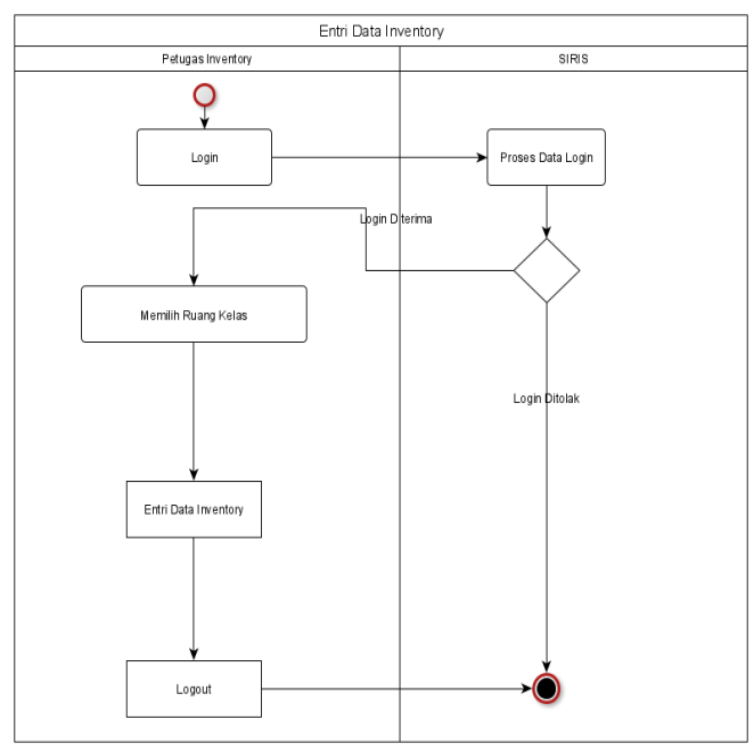

Gambar 4. Entri Data Inventory

Pada menu entri data inventory, Petugas Inventory diharuskan untuk melakukan entry inventory yang ada di ruang kelas agar dapat terdata secara terkomputerisasi.

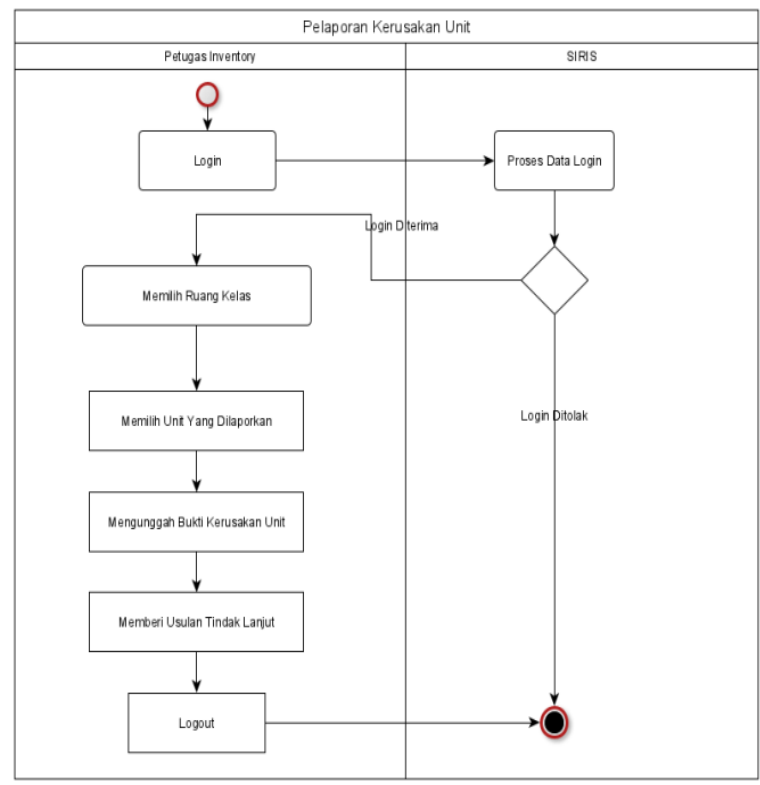

Gambar 5. Pelaporan Kerusakan Unit

Pada menu pelaporan kerusakan unit, Petugas Inventory dapat melaporkan apabila terjadi kerusakan unit pada inventory suatu ruang kelas. Pelaporan tersebut disertai bukti dan usulan tindaklanjutan.

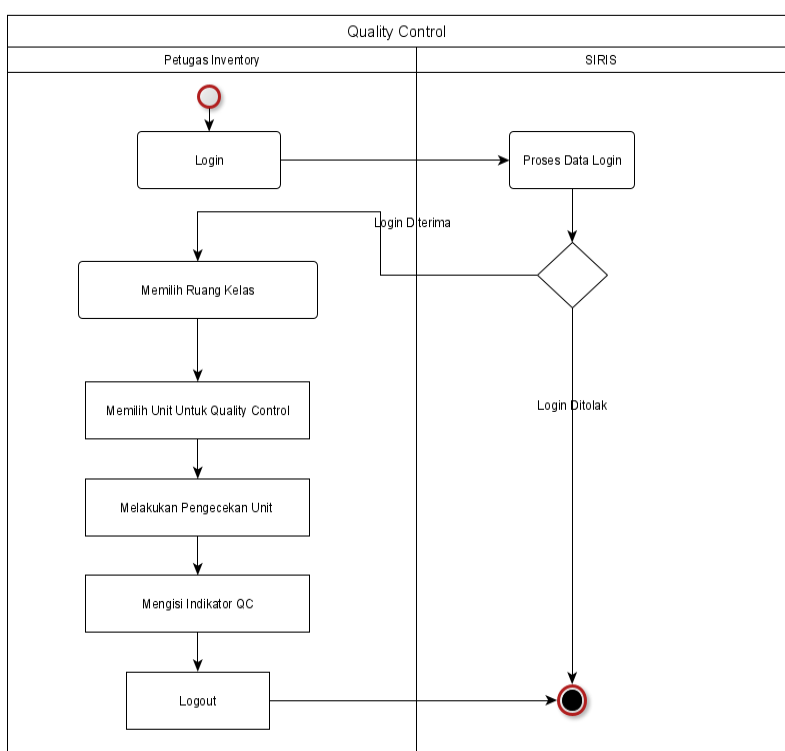

Gambar 6. Quality Control

Pada menu quality control, petugas inventory mampu melakukan pengecekan kualitas unit melalui beberapa indikator dengan cara statistical sampling. Akhir dari pengecekan kualitas tersebut akan terdokumentasikan dalam bentuk pelaporan.

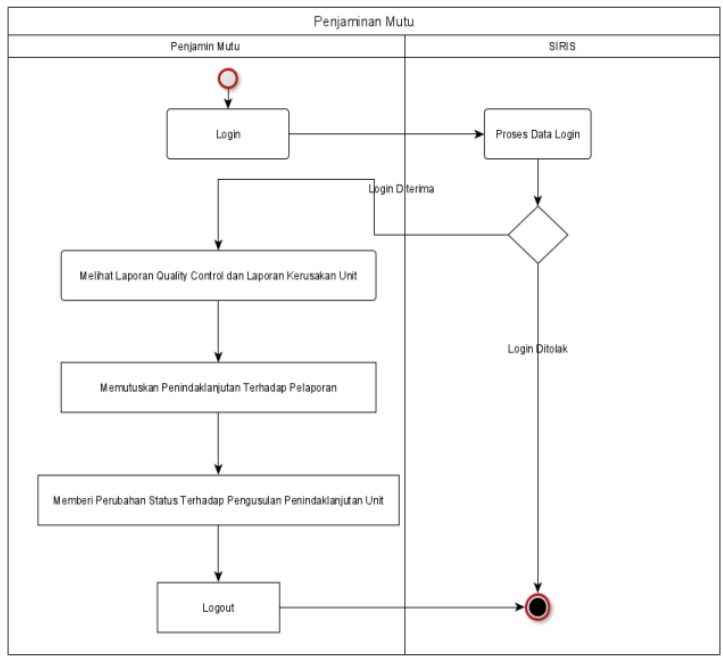

Gambar 7. Penjaminan Mutu

Pada menu laporan, Penjamin Mutu dapat melihat hasil dari laporan kerusakan unit, dan laporan quality control sebagai file penunjang. Hasil dari laporan tersebut dapat dijadikan bahan pertimbangan untuk melakukan penggantian unit, penghancuran unit, hingga pembelian unit baru. 


\section{Entity Relationship Diagram}

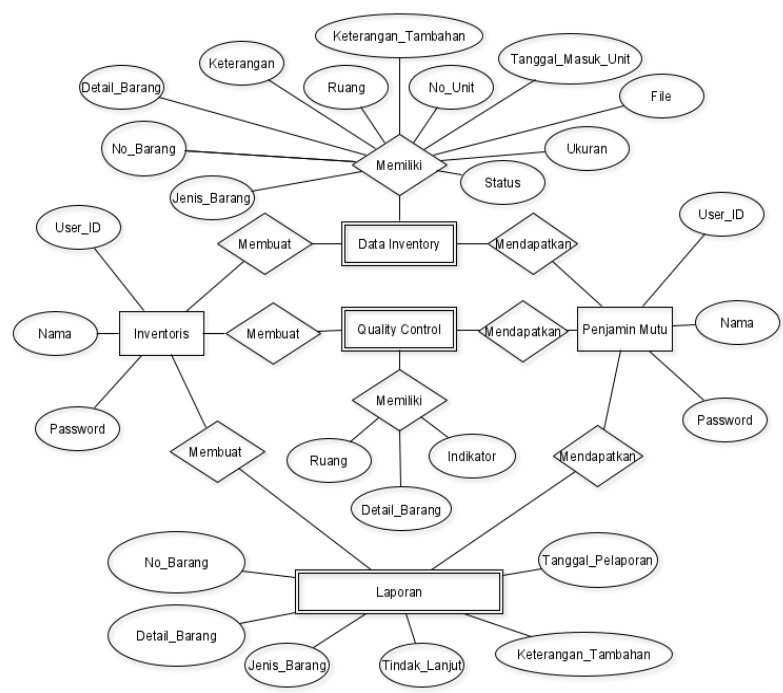

Gambar 8. ERD

Gambar diatas merupakan Entity Relationship Diagram (ERD) berupa notasi grafis dalam pemodelan data konseptual yang menggambarkan hubungan antara penyimpan yang terdapat didalam sistem.

\section{Perancangan Database}

Perancangan database dilakukan sesuai dengan kebutuhan dari sistem, dengan penjabaran sebagai berikut :

\begin{tabular}{|c|c|c|c|c|}
\hline & \multicolumn{4}{|c|}{$\mathrm{r}$} \\
\hline 2 & Ruang & Ruang & $\begin{array}{l}\text { Varch } \\
\text { ar }\end{array}$ & 50 \\
\hline 3 & $\begin{array}{l}\text { Jenis } \\
\text { Baran } \\
\mathrm{g} \\
\end{array}$ & $\begin{array}{l}\text { Jenis_Ba } \\
\text { rang }\end{array}$ & $\begin{array}{l}\text { Varch } \\
\text { ar }\end{array}$ & 100 \\
\hline 4 & $\begin{array}{l}\text { Detail } \\
\text { Baran } \\
\mathrm{g}\end{array}$ & $\begin{array}{l}\text { Detail_B } \\
\text { arang }\end{array}$ & $\begin{array}{l}\text { Varch } \\
\text { ar }\end{array}$ & 150 \\
\hline 5 & $\begin{array}{l}\text { Keter } \\
\text { angan }\end{array}$ & $\begin{array}{l}\text { Keterang } \\
\text { an }\end{array}$ & $\begin{array}{l}\text { Varch } \\
\text { ar }\end{array}$ & 500 \\
\hline 6 & $\begin{array}{l}\text { Keter } \\
\text { angan } \\
\text { Tamb } \\
\text { ahan }\end{array}$ & $\begin{array}{l}\text { Keterang } \\
\text { an_Tamb } \\
\text { ahan }\end{array}$ & $\begin{array}{l}\text { Varch } \\
\text { ar }\end{array}$ & 200 \\
\hline 7 & $\begin{array}{l}\text { Tangg } \\
\text { al } \\
\text { Masu } \\
\text { k Unit }\end{array}$ & $\begin{array}{l}\text { Tanggal_- } \\
\text { Masuk__ } \\
\text { Unit }\end{array}$ & Text & 25 \\
\hline 8 & $\begin{array}{l}\text { Ukura } \\
\mathrm{n}\end{array}$ & Ukuran & $\begin{array}{l}\text { Varch } \\
\text { ar }\end{array}$ & 255 \\
\hline 9 & File & File & $\begin{array}{l}\text { Varch } \\
\text { ar }\end{array}$ & 255 \\
\hline 10 & $\begin{array}{l}\text { No } \\
\text { Unit }\end{array}$ & No_Unit & $\begin{array}{l}\text { Varch } \\
\text { ar }\end{array}$ & 255 \\
\hline 11 & Status & Status & $\begin{array}{l}\text { Varch } \\
\text { ar }\end{array}$ & 100 \\
\hline
\end{tabular}

Tabel 1. Tabel User

No Elemen Akronim Type Size Kabel Data Inventory terdapat elemen utama yang terdiri dari No, Ruang, Jenis barang, detail barang, keterangan, keterangan

\begin{tabular}{|c|c|c|c|c|}
\hline 1 & ID & ID & Integer & $\mathrm{PK}_{\text {tambahan, tanggal masuk unit, ukuran, file. }}$ \\
\hline 2 & Level & Level & Integer & - nomor unit, dan status. \\
\hline 3 & Nama & Nama & Varchar 100 & 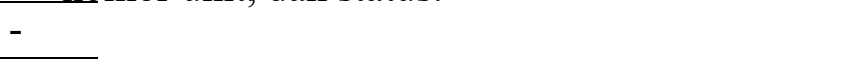 \\
\hline 4 & Password & Password & Varchar 50 & Tabel 3. Tabel Data Indikator Quality Contro \\
\hline
\end{tabular}

Tabel User terdapat 4 Eleme Akroni Type Size Ke \begin{tabular}{lllllll} 
terdiri dari ID, Level, Nama, dan Password. & o & n Data & m & & t. \\
\cline { 2 - 6 } & 1 & ID & ID & Integer & PK
\end{tabular}

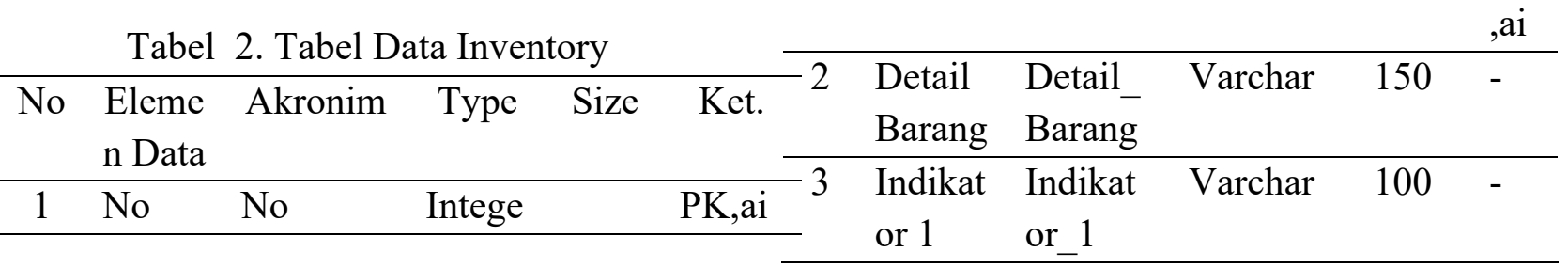




\begin{tabular}{llllll}
\hline 4 & $\begin{array}{l}\text { Indikat } \\
\text { or 2 }\end{array}$ & $\begin{array}{l}\text { Indikat } \\
\text { or_2 }\end{array}$ & Varchar & 100 & - \\
\hline 5 & $\begin{array}{l}\text { Indikat } \\
\text { or 3 }\end{array}$ & $\begin{array}{l}\text { Indikat } \\
\text { or_3 }\end{array}$ & Varchar & 100 \\
\hline 6 & $\begin{array}{l}\text { Indikat } \\
\text { or 4 }\end{array}$ & $\begin{array}{l}\text { Indikat } \\
\text { or_4 }\end{array}$ & Varchar & 100 \\
\hline 7 & $\begin{array}{l}\text { Indikat } \\
\text { or 5 }\end{array}$ & $\begin{array}{l}\text { Indikat } \\
\text { or_5 }\end{array}$ & Varchar & 100 \\
\hline 8 & $\begin{array}{l}\text { Status } \\
\text { QC }\end{array}$ & $\begin{array}{l}\text { Status_ } \\
\text { QC }\end{array}$ & Varchar & 100 \\
\hline
\end{tabular}

Tabel Data Hasil Quality Control terdapat elemen utama yang terdiri dari No, ruang, detail barang, jumlah unit, sampel, hasil, tanggal quality control, dan keterangan quality control.

Tabel 5. Tabel Data Laporan Kerusakan Unit

\begin{tabular}{cccccc} 
No & $\begin{array}{c}\text { Eleme } \\
\text { n Data }\end{array}$ & Akronim & Type & $\begin{array}{c}\text { Siz } \\
\text { e }\end{array}$ & $\begin{array}{c}\mathrm{Ke} \\
\mathrm{t} .\end{array}$ \\
\hline 1 & No & No & Integ & & PK
\end{tabular}

Tabel Data Indikator Quality Control terdapat elemen ID, Detail Barang, Indikator, dan Status Quality Control.

Tabel 4. Tabel Data Hasil Quality Control

\begin{tabular}{|c|c|c|c|c|c|}
\hline No & $\begin{array}{l}\text { Eleme } \\
\text { n Data }\end{array}$ & Akronim & Type & $\begin{array}{c}\text { Siz } \\
\text { e }\end{array}$ & $\begin{array}{c}\mathrm{Ke} \\
\mathrm{t} .\end{array}$ \\
\hline 1 & No & No & Integ & & PK \\
\hline & & & er & & ,ai \\
\hline 2 & Ruang & Ruang & Varc & 150 & - \\
\hline & & & har & & \\
\hline 3 & Detail & Detail_Bar & Varc & 100 & - \\
\hline & Barang & ang & har & & \\
\hline 4 & Jumlah & Jumlah_Un & Integ & & - \\
\hline & Unit & it & er & & \\
\hline 5 & Sampe & Sampel & Integ & & \\
\hline & 1 & & er & & \\
\hline 6 & Hasil 1 & Hasil_1 & Integ & & \\
\hline & & & er & & \\
\hline 7 & Hasil 2 & Hasil_2 & Integ & & \\
\hline & & & er & & \\
\hline 8 & Hasil 3 & Hasil 3 & Integ & & \\
\hline & & & er & & \\
\hline 9 & Hasil 4 & Hasil_4 & Integ & & \\
\hline & & & er & & \\
\hline 10 & Hasil 5 & Hasil_5 & Integ & & \\
\hline & & & er & & \\
\hline 11 & Tangg & Tanggal_Q & Text & 100 & \\
\hline & al QC & $\mathrm{C}$ & & & \\
\hline 12 & Ketera & Keterangan & Varc & 200 & \\
\hline & ngan & _QC & har & & \\
\hline & QC & & & & \\
\hline
\end{tabular}

\begin{tabular}{llllll} 
& & & er & & ,ai \\
\hline 2 & No & No_Barang & Integ & 150 & - \\
& Barang & & er & & \\
\hline 3 & Jenis & Jenis_Bara & Varc & 100 & - \\
& Barang & ng & har & & \\
\hline 4 & Detail & Detail_Bar & Varc & 100 & -
\end{tabular}

\begin{tabular}{llllll}
\hline 4 & $\begin{array}{l}\text { Detail } \\
\text { Barang }\end{array}$ & $\begin{array}{l}\text { Detail_Bar } \\
\text { ang }\end{array}$ & $\begin{array}{l}\text { Varc } \\
\text { har }\end{array}$ & & - \\
\hline
\end{tabular}

\begin{tabular}{lllll}
\hline 5 & $\begin{array}{l}\text { Ketera } \\
\text { ngan }\end{array}$ & Keterangan & $\begin{array}{l}\text { Varc } \\
\text { har }\end{array}$ & \\
\hline
\end{tabular}

6 Ket. Keterangan Varc 100
Tamba_Tambahan har han

\begin{tabular}{lllll}
\hline 7 & $\begin{array}{l}\text { Tangg } \\
\text { al } \\
\text { Masuk }\end{array}$ & $\begin{array}{l}\text { Tanggal_M } \\
\text { asuk_Unit }\end{array}$ & $\begin{array}{l}\text { Varc } \\
\text { har }\end{array}$ & 50 \\
& Unit & & & \\
\hline 8 & Ukura & Ukuran & Varc & 255 \\
& $\mathrm{n}$ & & har & \\
\hline 9 & File & File & Varc & 255 \\
& & & har & \\
\hline
\end{tabular}

10 No No_Unit Integ
Unit er

11 Status Status TinyI 100

\begin{tabular}{cllll} 
& & \multicolumn{3}{c}{ nt } \\
\hline 12 & $\begin{array}{l}\text { Tindak } \\
\text { Lanjut }\end{array}$ & $\begin{array}{l}\text { Tindak_La } \\
\text { njut }\end{array}$ & $\begin{array}{l}\text { Varc } \\
\text { har }\end{array}$ & 200 \\
\hline 13 & $\begin{array}{l}\text { Ket.La } \\
\text { njutan }\end{array}$ & $\begin{array}{l}\text { Keterangan } \\
\text { Lanjutan }\end{array}$ & $\begin{array}{l}\text { Varc } \\
\text { har }\end{array}$ & 100 \\
\hline 14 & $\begin{array}{l}\text { Tangg } \\
\text { al }\end{array}$ & $\begin{array}{l}\text { Tanggal_Pe } \\
\text { laporan }\end{array}$ & Text & 50 \\
& $\begin{array}{l}\text { Pelapo } \\
\text { ran }\end{array}$ & & & \\
\hline 15 & Ukura & Ukuran2 & Varc & 255 \\
\hline
\end{tabular}




\begin{tabular}{llll}
\hline \multicolumn{1}{c}{$\mathrm{n}$ File } & & har & \\
& Eviden & & \\
& ce & & \\
\hline 16 & File & File2 & Varc 255 \\
& $\begin{array}{l}\text { Eviden } \\
\text { ce }\end{array}$ & har & \\
& & & \\
\hline
\end{tabular}

Tabel data laporan kerusakan unit terdapat elemen utama yang terdiri dari No, nomor barang, jenis barang, detal barang, keterangan, keterangan tambahan, tanggal masuk unit, ukuran, file, nomor unit, status, tindaklanjut, keterangan lanjutan, tanggal pelaporan, ukuran file evidence, dan file evidence.

\section{Tampilan Sistem}

Tampilan sistem dimulai dengan halaman login yang berguna untuk memverifikasi pengguna sistem sesuai dengan ID pengguna dan kata sandi yang telah diberikan.

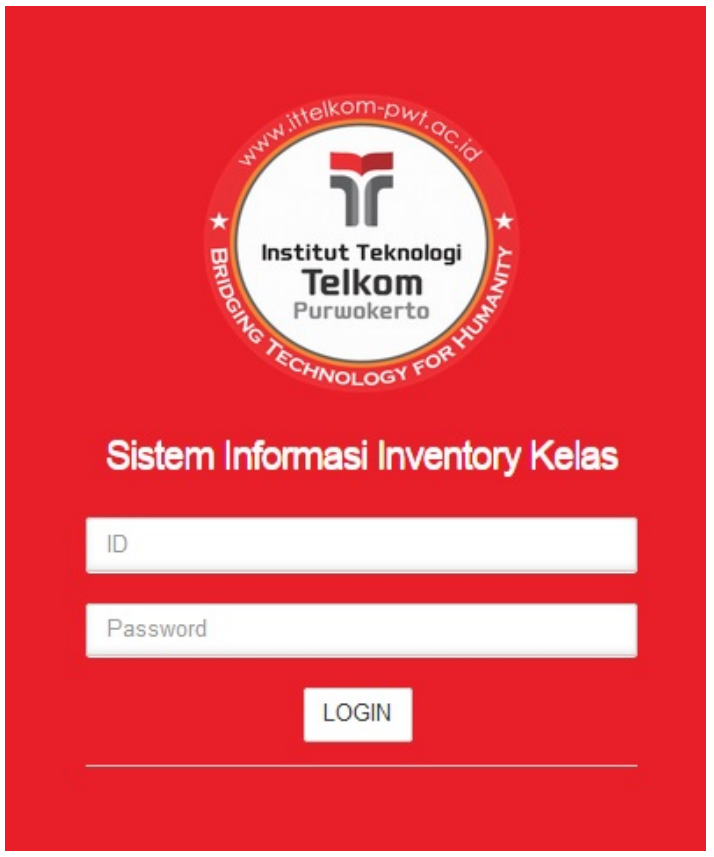

Gambar 9. Tampilan Login

Setelah sukses melakukan login, fitur yang pertama dapat diakses adalah halaman beranda yang menampilkan halaman utama sistem.
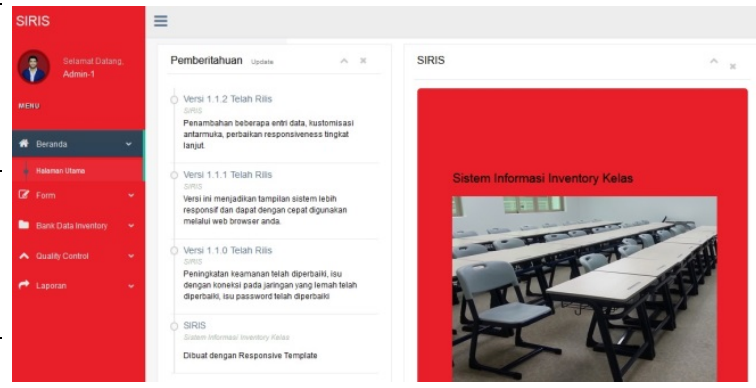

Gambar 10. Tampilan Beranda

Untuk melakukan entri data, pengguna sistem (Petugas inventory) dapat mengakses fitur penambahan data inventory untuk kemudian memilih ruangan yang tersedia di ITTP sesuai dengan pilihan dan denah ruangan.
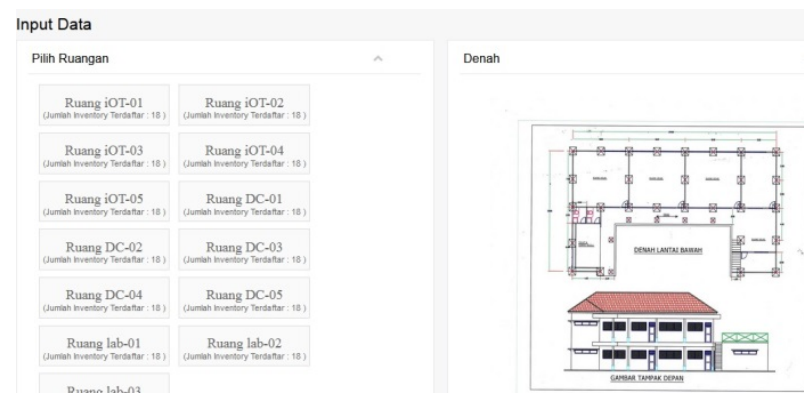

Gambar 11. Tampilan Pilihan Ruangan

Setelah memilih ruangan, pengguna dapat memasukkan data sesuai dengan entitas yang tersedia

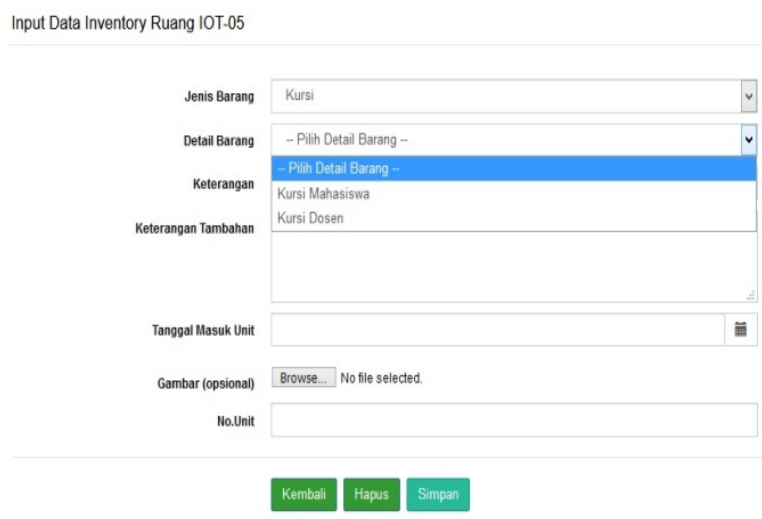

Gambar 12. Tampilan Entri Data

Data yang telah dientri kemudian akan tersimpan kedalam suatu bank data inventory. 


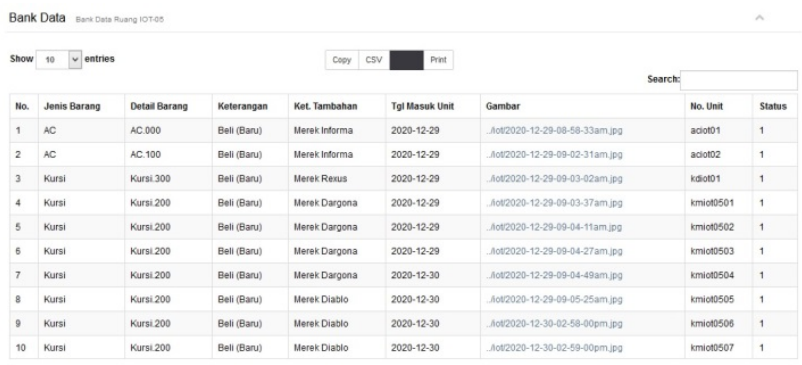

Gambar 13. Tampilan Bank Data

Proses quality control dimulai dengan cara mengisikan data sesuai dengan indikator quality control yang telah tersedia
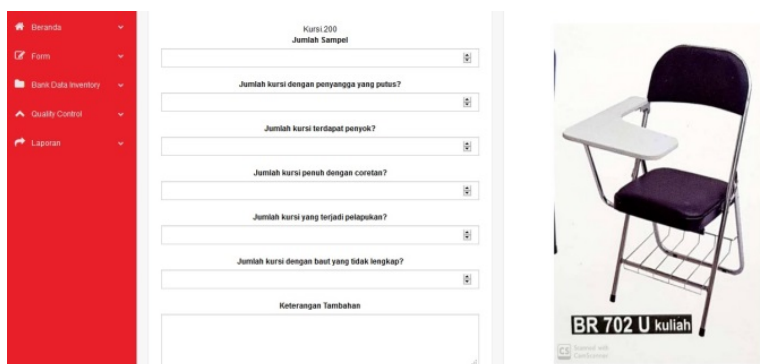

Gambar 14. Tampilan Pengisian QC

Data hasil proses quality control kemudian disimpan ke dalam suatu bentuk pelaporan untuk kemudian dapat digunakan sebagai proses pengambilan keputusan maupun penjaminan mutu inventory kelas.

\begin{tabular}{|c|c|}
\hline 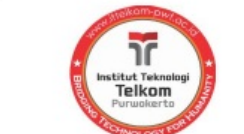 & $\begin{array}{l}\text { INSTITUT TEKNOLOGI TELKOM } \\
\text { PURWOKERTO } \\
\begin{array}{l}\text { J1. DI Panjaltan No.128, Karangreja, Purwokerto KIdul, Kec. Purwokerto } \\
\text { Sel., }\end{array} \\
\text { Kabupaten Banyumas, Jawa Tengah } 53147\end{array}$ \\
\hline \multicolumn{2}{|c|}{ HASIL QUALTTY CONTROL INVENTORY KELAS } \\
\hline Ruang : 10T-05 & Tanggal Pemeriksaan : 2021-01-01-09-09-10pm \\
\hline Detall Barang : Kurss1.200 & Jumlah Unit : 10 \\
\hline \multicolumn{2}{|r|}{ Sampel : 4} \\
\hline $\begin{array}{l}\text { Jumlah kursı dengan penyangga yang } \\
\text { putus? }\end{array}$ & $: 1$ Unit \\
\hline Jumlah kursı terdapat penyok? & : 0 Unit \\
\hline Jumlah kurst penuh dengan coretan? & $: 2$ Unit \\
\hline Jumlah kurst yang terjadl pelapukan? & $: 1$ Unit \\
\hline $\begin{array}{l}\text { Jumlah kursı dengan baut yang tidak } \\
\text { lengkap? }\end{array}$ & $: 1$ Unit \\
\hline
\end{tabular}

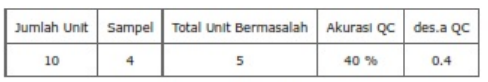

Operator : Diovianto

Gambar 15. Tampilan Laporan QC

Selain itu juga terdapat menu pelaporan kerusakan pada inventory apabila terdapat kerusakan maupun usulan pengadaan mengenai pengadaan inventory baru.
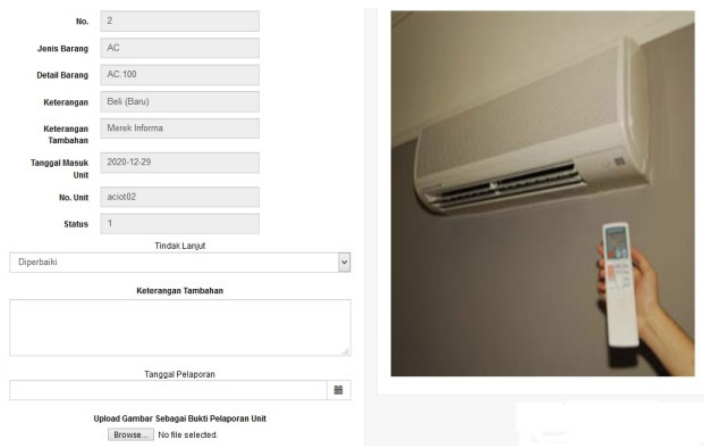

Gambar 16. Tampilan Pelaporan Kerusakan

\section{KESIMPULAN}

Dengan adanya sistem inventory ruang kelas berbasis web dengan metode quality control, pelaporan mengenai inventory hingga kendali mutu mampu menjawab segala kebutuhan di ITTP. Dengan adanya suatu sistem terkomputerisasi, kini setiap inventory yang ada dalam suatu ruang kelas dapat terdaftar di suatu database milik ITTP, dan mudah untuk dilacak, dipantau kualitasnya, hingga pelaporan kerusakan inventory yang semakin mudah. Dengan adanya sistem ini, maka segala kendala yang dihadapi dalam hubungannya dengan inventory mampu terjawab dan proses pengendalian mutu (Quality Control) yang terkomputerisasi terbukti membantu pihak inventory ITTP dalam memantau kualitas inventory yang ada.

Untuk penelitian selanjutnya, disarankan untuk memberi tambahan indikator mengenai quality control, penambahan inventory yang dapat dikomputerisasi, hingga penindaklanjutan terhadap kerusakan inventory yang terkomputerisasi.

\section{DAFTAR PUSTAKA}

[1] J. E. Leedy, Paul D; Ormrod, Systems Analysis and Design Ninth Edition. 2010.

[2] James A. O'Brien and G. M. Marakas, Management System Information. 2010. 
[3] Arief, "Pemograman web dinamis menggunakan php dan mysql. Yogyakarta," Yogyakarta C.V ANDI OFFSET., 2011.Nugroho (2004)

[4] Nugroho, Bunafit. PHP \& My SQL dengan Editor Dreamweaver MX, Penerbit Andi Offset, Jogjakarta, 2004

[5] Gaspersz, Vincent. 2005. Sistem Manajemen Kinerja Terintegrasi Balanced Scorecard Dengan Six Sigma Untuk Organisasi Bisnis dan Pemeritah. Jakarta:Gramedia Pustaka Utama.

[6] E. P. Membara, L. Yulianti, and I. Kanedi, "Sistem Informasi Akademik Smp Negeri 2 Talang Empat Berbasis Web," media Inform., 2014.

[7] W. Handiwidjojo, "Sistem Informasi Manajemen Rumah Sakit," J. EKSIS, 2010.

[8] D. P. Rakhmadani and S. R. Wicaksono, "Sistem Informasi Pengukuran Efektivitas Produksi BerbasisWeb (Studi Kasus : PT. Beiersdorf Indonesia)," J. Rekayasa Sist. Ind., 2015, doi: 10.26593/jrsi.v4i2.1628.70-76.

[9] M. Susanti, "Perancangan Sistem Informasi Akademik Berbasis Web Pada Smk Pasar Minggu Jakarta," Informatika, 2016.

[10] Sutarti, Sutriyono, and D. Gustopo, "Analisis Pengendalian Persediaan Bahan Baku Menggunakan Metode Economic Order Quantity dalam Upaya Meningkatkan Efisiensi (Studi Kasus pada PT. Pancaran Mulia Sejati)," J. Teknol. dan Manaj. Ind., 2016. 